\title{
Flavonoids and Arbutin from Turnera diffusa
}

Sonia Piacente ${ }^{\mathrm{a}}$, Ely E. S. Camargo ${ }^{\mathrm{b}}$, Aurelia Zampelli ${ }^{\mathrm{a}}$, Juliano S. Gracioso ${ }^{\mathrm{c}}$,

Alba R. Souza Brito ${ }^{c}$, Cosimo Pizza ${ }^{\mathrm{a}}$ and Wagner Vilegas ${ }^{\mathrm{d} *}$

a Dipartimento di Scienze Farmaceutiche, Università degli Studi di Salerno,

Via Ponte don Melillo, 84084, Fisciano (SA), Italy

b Faculdade de Ciências Farmacêuticas-UNESP, CP 502 Araraquara, SP, Brazil, CEP 14801-902

c Instituto de Biologia-UNICAMP, Departamento de Fisiologia e Biofísica, CP 6109, Campinas, SP, Brazil, CEP 13083-970

d Instituto de Química de Araraquara-UNESP, Departamento de Química Orgânica, R. Prof. Francisco Degni s/n, CP 355 Araraquara, SP, Brazil, CEP 14801-970. Fax +55-16-2227932. E-mail: vilegasw@iq.unesp.br

* Author for correspondence and reprint requests

Z. Naturforsch. 57c, 983-985 (2002); received June 10/August 2, 2002

Turnera diffusa, Flavonoids

The infusion of the aerial parts of Turnera diffusa was phytochemically examined. Chromatographic procedures led to the isolation of a new flavone glycoside, five known flavonoids and p-arbutin. Structures were determined by 1D- and 2D NMR experiments, as well as ES-MS and UV spectra.

\section{Introduction}

Turnera diffusa Wild. (Turneraceae) with the common name "damiana" is a small shrub that grows in North and South America and Africa. Aerial parts of Turnera ssp are popularly used for the treatment of diseases related to the gastric systems (Weniger et al, 1986). We have previously reported the anti-inflammatory and anti-ulcer activity of the aerial parts of T. ulmifolia L or "chanana", a species that presents similar morphology with T. diffusa (Antonio and Brito, 1998). Despite the infusion from the aerial parts of $T$. diffusa is used in the folk medicine as anti-ulcer, its chemical constituents were not described until now. Therefore, we decide to perform the phytochemical investigation of the infusion.

\section{Material and Methods}

\section{General}

Spectra were recorded using the following instruments: IR: Nicolet impact 400, KBr; UV: HP 8472-A spectrometer $(\mathrm{MeOH}, \mathrm{c}=1)$; NMR: Bruker DRX-spectrometer $(600 \mathrm{MHz})$, Varian Inova 500 $(500 \mathrm{MHz})$, solvents $\mathrm{CD}_{3} \mathrm{OD}$, DMSO-d 6 , TMS as internal standard; ESMS (positive mode): Fisons Platform; GPC: Sephadex LH-20 (Pharmacia); preparative HPLC: Varian ProStar 210, Varian 350 refractive index detector, Luna C-18 Phenomenex column $250 \mathrm{~cm} \times 10 \mathrm{~mm}$ i. d. $\times 10 \mu \mathrm{m}, 50 \% \mathrm{MeOH}$, $2.0 \mathrm{ml} \mathrm{min}^{-1}$.

\section{Plant material}

Turnera diffusa Wild. was collected at Quintana Roo, Mexico, in January, 2000. Voucher samples were deposited at the herbario of the Centro de Investigación Científica del Yucatan under number C. Chan 3773.

\section{Preparation of the infusion, fractionation and purification of compounds}

The aerial parts of $T$. diffusa were dried in an oven at $40^{\circ} \mathrm{C}$ and milled. The powder (200 g) was extracted overnight with boiling water $(21)$. The mixture was filtrated and lyophylized, affording ca. $7.5 \mathrm{~g}$. An aliquot of $2 \mathrm{~g}$ of the lyophylized infusion was resuspended in $\mathrm{MeOH}$, centifuged and chromatographed on a Sephadex LH-20 column

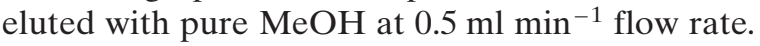
100 fractions of $5 \mathrm{ml}$ were collected. After TLC analysis (silica-gel, n-BuOH-HOAc-water 65:15:25 $\mathrm{v} / \mathrm{v} / \mathrm{v}$ ) plates were sprayed with NP/PEG reagent (Wagner et al., 1986), fractions with similar Rf's were recombined and further purified by reversed- 
phase HPLC ( $\mu$-Bondapak C-18 Waters column $30 \mathrm{~cm} \times 7.8 \mathrm{~mm}$ i.d., $50 \% \mathrm{MeOH}, 2.0 \mathrm{ml} \mathrm{min}^{-1}$ ) to give compound $\mathbf{1}(25 \mathrm{mg}), \mathbf{2}(35 \mathrm{mg}), \mathbf{3}(250 \mathrm{mg})$, $4(25 \mathrm{mg}), 5(20 \mathrm{mg})$ and $\mathbf{6}(25 \mathrm{mg})$ and p-arbutin 7 (75 mg).

\section{Results and Discussion}

The infusion from the aerial parts of T. diffusa was chromatographed on a Sephadex LH-20 column. The fractions containing flavonoids, checked by TLC plates and visualized with NP-PEG reagent, were further purified by reversed phase HPLC to give compounds 1-6 (Fig. 1). The structures of all compounds were determined by $1 \mathrm{D}$ and 2D NMR experiments, positive ESMS spectra and UV data. Of the isolated metabolites, compound $\mathbf{1}$ is new. The known compounds $\mathbf{2 - 6}$ were identified by comparison of their spectroscopic data with those already reported (Agrawal, 1996; Harborne, 1996; Ahmed et al., 2000).
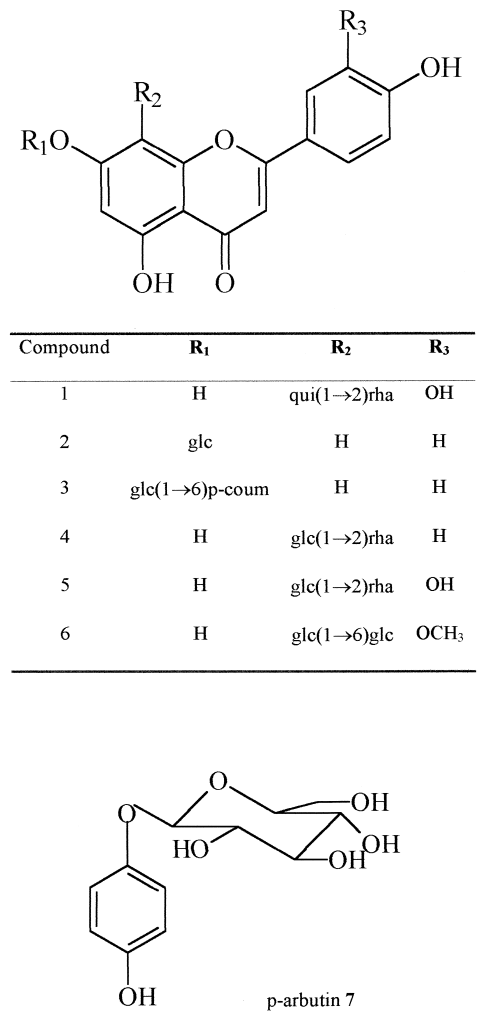

Fig. 1. Compounds isolated from the infusion of Turnera diffusa.
Compound 1 was first identified as a flavonoid based on its orange spot on TLC plate visualized with NP-PEG reagent (Wagner et al., 1986). The UV spectrum presented bands at 260 and $350 \mathrm{~nm}$. The IR presented bands at 3300, 2912 and $1650 \mathrm{~cm}^{-1}$. The ESMS spectrum of 1 exhibited protonated molecular ion $[\mathrm{M}+\mathrm{H}]^{+}$at $\mathrm{m} / z, 579$ corresponding to molecular formula $\mathrm{C}_{27} \mathrm{H}_{30} \mathrm{O}_{14}$. Loss of 146 mass units led to the fragment ion at $\mathrm{m} / \mathrm{z}$ 433. The protonated aglycone fragment was not observed. The ${ }^{1} \mathrm{H}$ NMR spectrum of $\mathbf{1}$ (Table I) displayed signals corresponding to a trisubstituted B-ring of the flavonoid nucleus at $\delta 7.50(1 \mathrm{H}$, dd, $\left.J=8.0,2.0 \mathrm{~Hz}, \mathrm{H}-6^{\prime}\right), 7.46\left(1 \mathrm{H}, \mathrm{d}, J=2.0 \mathrm{~Hz}, \mathrm{H}-2^{\prime}\right)$ and $6.89\left(1 \mathrm{H}, \mathrm{d}, J=8.0 \mathrm{~Hz}, \mathrm{H}-5^{\prime}\right)$ (Table I). Two singlets appeared at $\delta 6.46(1 \mathrm{H}, \mathrm{H}-3)$ and $6.15(1 \mathrm{H}$, H-6). Two anomeric protons were observed at $\delta 5.11(1 \mathrm{H}, \mathrm{d}, J=1.5 \mathrm{~Hz})$ and $5.10(1 \mathrm{H}, \mathrm{d}, J=$ $7.5 \mathrm{~Hz})$. Two doublets $(J=6.5 \mathrm{~Hz})$ integrating for $3 \mathrm{H}$ each were visible at $\delta 1.42$ and 0.72 . The remaining sugar protons appeared in the range

Table I. ${ }^{1} \mathrm{H}$ - and ${ }^{13} \mathrm{C}-\mathrm{NMR}$ spectral data for compound 1 (600 and $175 \mathrm{MHz}$ in $\mathrm{CD}_{3} \mathrm{OD}, J$ in $\mathrm{Hz}$ ).

\begin{tabular}{crl}
\hline Position & $\delta \mathrm{C}$ & $\delta \mathrm{H}$ \\
\hline 2 & 166.5 & \\
3 & 103.1 & $6.46 \mathrm{~s}$ \\
4 & 183.0 & \\
5 & 157.1 & \\
6 & 101.8 & $6.15 \mathrm{~s}$ \\
7 & 163.9 & \\
8 & 105.9 & \\
9 & 158.5 & \\
10 & 104.2 & \\
$1^{\prime}$ & 123.9 & \\
$2^{\prime}$ & 114.2 & $7.46 \delta(2.0)$ \\
$3^{\prime}$ & 147.3 & \\
$4^{\prime}$ & 151.2 & \\
$5^{\prime}$ & 116.7 & $6.89 \delta(8.0)$ \\
$6^{\prime}$ & 121.1 & $7.50 \mathrm{dd}(8.0,2.0)$ \\
Quinovose & & \\
$1^{\prime \prime}$ & 73.9 & $5.10 \delta(7.0)$ \\
$2^{\prime \prime}$ & 78.4 & $4.33 \mathrm{dd}(7.0,9.0)$ \\
$3^{\prime \prime}$ & 81.4 & $3.60 \mathrm{dd}(9.0,9.0)$ \\
$4^{\prime \prime}$ & 78.0 & $3.45 \mathrm{dd}(9.0,9.0)$ \\
$5^{\prime \prime}$ & 78.1 & $3.53 \mathrm{~m}$ \\
$6^{\prime \prime}$ & 17.7 & $1.42 \delta(6.5)$ \\
Rhamnose & & \\
$1^{\prime \prime \prime}$ & 102.7 & $5.11 \delta(1.5)$ \\
$2^{\prime \prime \prime}$ & 72.3 & $3.86 \mathrm{dd}(1.5,3.0)$ \\
$3^{\prime \prime \prime}$ & 71.6 & $3.49 \mathrm{dd}(3.0,9.0)$ \\
$4^{\prime \prime \prime}$ & 73.9 & $3.11 \mathrm{dd}(9.0,9.0)$ \\
$5^{\prime \prime \prime}$ & 69.9 & $2.66 \mathrm{~m}(6.5)$ \\
$6^{\prime \prime \prime}$ & 17.3 & $0.72 \delta(6.5)$ \\
\hline & &
\end{tabular}


$\delta 4.33-2.56$. The ${ }^{13} \mathrm{C}$ NMR spectrum of $\mathbf{1}$ (Table I) revealed 27 carbon signals, 15 of which were assigned to a luteolin unit. The anomeric carbons absorbed at $\delta 102.7$ and 73.9, while the methyl carbons appeared at $\delta 17.3$ and 17.7. 1D-TOCSY combined to DQF-COSY experiments afforded the spin sequences of the two sugar moieties. Irradiation of the methyl signal at $\delta 0.72$ led to the set of resonances at $\delta 2.66,3.11,3.49$ and 3.86. On the basis of the coupling constants this spin system was identified as a rhamnose unit. Irradiation of the methyl signal at $\delta 1.42$ showed the sequence $3.45,3.53,3.60,4.33,5.10$ which, on the basis of the coupling constants, allowed the identification of a quinovose unit (Table I). The recognition of all proton resonances for the sugar moieties allowed to assign the resonances of the linked carbons by HSQC (Table I) and substantiated the presence of luteolin, rhamnose and quinovose unitis. The HMBC spectrum showed correlations between the proton at $\delta 5.10$ (H-1"-qui) with $\mathrm{C}-8$ of the aglycone $(\delta 105.9)$, and between the proton signal at $\delta 5.11$ (H-1"'-rha) with $\mathrm{C}-2$ of the quinovose unit $(\delta 78.4)$. The coupling constants of the anomeric protons (Table I) indicated the $\alpha$-configuration of the rhamnose unit and the $\beta$-configuration of the quinovose moiety. On the basis of these findings, compound $\mathbf{1}$ was deduced to be the new luteolin-8-C- $\alpha$-L-rhamnopyranosyl $(1 \rightarrow 2)$ quinovopyranoside.

The antiulcerogenic activity of many plant species has already been related to their flavonoid content (Yesilada et al., 2000; Lewis and Hanson, 1991). Therefore, the folk usage of the infusion of T. diffusa may be supported by these compounds. Further investigations are under way to determine the role of these flavonoids.

\section{Acknowledgments}

We thank to Fapesp for fundings and for a fellowship to JG and to Conselho Nacional de Desenvolvimento Científico for grants to ARSB and WV.
Agrawal P. K. (1989), Carbon-13 NMR of Flavonoids. Elsevier, New York, 564 pp.

Ahmed A. S., Nakamura N., Meselhy M. R., Makhboul M. A., El-Emary N. and Hattori M. (2000), Phenolic constituents from Grevillea robusta. Phytochemistry $\mathbf{5 3}, 149-54$.

Antonio M. A. and Souza Brito A. R. M. (1998), Oral anti-inflammatory and anti-ulcerogenic activities of a hydroalcoholic extract and partitioned fractions of Turnera ulmifolia (Turneraceae). J. Ethnopharmacol. 61, 215-228.

Harborne J. B. (1996), The Flavonoids. Advances in Research since 1986. Chapman and Hall, London, 675 pp.
Lewis D. A. and Hanson P. J. (1991), Anti-ulcer drugs of plant origin. Progr. Med. Chem. 28, 201-231.

Wagner H. M., Bladt S. and Zgainski E. M. (1986), Plant Drug Analysis. Springer, Berlin, p. 303.

Weniger B., Rouzier M., Daguilh R., Henrys D., Henrys J. H. and Anton T. (1986), Popular medicine of the Central Plateau of Haiti 2. J. Ethnopharmacol. 171, 13-30.

Yesilada E., Tsuchiya K., Takaishi Y. and Kazuyoshi K. (2000), Isolation and characterization of free radical scavenging flavonoid glycosides from the flowers of Spartium junceum by activity-guided fractionation. J. Ethnopharmacol. 73, 471-478. 